\title{
The optimal choice of privatizing state-owned enterprises: A political economic model*
}

\author{
YAN CHEN \\ Department of Economics, The University of Michigan, Ann Arbor, M148109-1220, U.S.A.
}

Accepted 5 April 1994

\begin{abstract}
We study the choices of two types of maximizing Public Servants over how far to carry privatization of industries and in what order to privatize. Two stylizations of the Public Servant's objectives are considered, a Niskanen-style Bureaucrat who maximizes a surplus budget subject to the constraint of staying in office, and a Populist who maximizes popularity/consumer welfare subject to the constraint of a balanced budget. Other things being equal, the Bureaucrat will privatize the sector (firms) with the least market power and the largest subsidy first. The Populist will adopt the same policy, if the marginal costs of products in the private sectors are not too high with respect to the marginal utilities. If the marginal costs are too high, however, the Populist will privatize the sector with the largest market power first. We also show that privatization is easier and faster in less democratic societies.
\end{abstract}

\section{Introduction}

Because of the universally recognized deficiencies of state-owned enterprises compared to private enterprises, there is almost no controversy over the necessity to transform central-planned economies into market economies. The controversy lies in how to perform the transition and the extent of the transition. This paper builds on a model of transition economy in which a Public Servent, i.e., a politician, with different objectives and under different political institutions, must decide how far to carry privatization and in what order to privatize.

Debates over privatization policies among economists usually focus on the sequencing problem, i.e., how to find the optimal sequence of privatization so as to minimize the problems characterizing the transition period. The sequence

\footnotetext{
* I thank John Ledyard, Kim Border, Morgan Kousser, Peter Ordeshook and Tom Palfrey for their advice and suggestions. I have also benefited from helpful criticism from Michael Alexeev, Kay-yut Chen, Peng Lian, Scott Page, Friedrich Schneider, Katerina Sherstyuk, and Langche Zeng. A special note of thanks goes to Ron Harstad for his encouragement and for suggesting key expositional improvements. Financial assistance from the Flight Projects Office of the Jet Propulsion Laboratory of NASA to the Program on Organization Design is greatly appreciated. Any remaining errors are my own.
} 
suggested and practiced in these countries roughly follows the size of different sectors (Li, 1989; Blommesteine and Marrese, 1991): rapid privatization of small businesses first; establishment of a social safety net; demonopolization; privatization of medium state-owned enterprises; and last, privatization of large state-owned enterprises.

Despite the heated discussions and various experiments over sequencing, there is virtually no theoretically work on sequencing. In particular, there is no formal model in the privatization literature that incorporates the influence of politics on privatization policies. We need to remember that politicians choose the privatization policies. Therefore, it is important to see what kind of politics a maximizing politician would choose under different political institutions.

In this paper, we set up a model to test the rationale of the sequence suggested above by economists of central planned economies and to study what kind of sequence a Public Servant with different objectives would choose. Some features of the model, including the compensation scheme, are abstracted from the Chinese experience. We want to see what kind of sequence is optimal for a Public Servant in the context of a controlled privatization process. Section 2 introduces a two period model of a highly simplified transition economy. Section 3 presents the analysis of the problem of the consumer, the firm, and the Public Servant respectively. Two types of Public Servants are considered: one who maximizes the surplus budget subject to the constraint of staying in office - the Bureaucrat, and one who maximizes popularity/consumer welfare subject to the constraint of a balanced budget - the Populist. Section 4 contains the main results of the model: other things being equal, the Bureaucrat will privatize the sector (firms) with the least market power ${ }^{1}$ and the largest subsidy first. The Populist will adopt the same policy, if the marginal costs of products in the private sectors are not too high. Therefore, the result is quite robust to the specification of the politician's objectives. Also, we show that it can be relatively easier and faster to privatize in a less democratic society. Finally, in Section 5, we discuss the limitations and possible extensions of the model and conclude the paper.

\section{Setup and basic assumptions}

This section presents a simplified two period model of a transition economy that consists of I consumers, $N+1$ sectors of firms, and a Public Servant.

Consumers have different utility functions and incomes, which are exogenously given. At time $t$, consumer $i$ is rationed to a fixed amount of products from the public sectors at fixed prices. Because of the low prices and minimum amounts supplied, we assume that he buys all the quantities that are rationed to him. This assumption closely approximates the actual situations in 
many central planned economies. He uses the rest of his income to choose consumption bundles from the products of the private sectors to maximize his utility.

Assumption 1. Each consumer has a quasilinear utility function, $\mathrm{u}_{\mathrm{i}}\left(\mathrm{q}_{0}, \mathrm{q}_{1}, \ldots\right.$, $\left.\mathrm{q}_{\mathrm{N}}\right)=\mu_{\mathrm{i}}\left(\mathrm{q}_{1}, \ldots, \mathrm{q}_{\mathrm{N}}\right)+\mathrm{q}_{\mathrm{i} 0}$, where $\mathrm{q}_{1}, \ldots \mathrm{q}_{\mathrm{N}}$ are the amounts of products $1, \ldots$, $\mathrm{N}$ he consumes, and $\mathrm{q}_{0}$ is a numeraire good $\left(\mathrm{p}_{0}=1\right)$ s.t.

(i) $\mathrm{u}: \mathrm{R}_{+}^{\mathrm{N}+1} \rightarrow \mathrm{R}_{+}^{1}$ is monotonically increasing;

(ii) $u$ is twice continuously differentiable, and strictly concave;

(iii) u satisfies the following Inada conditions:

$$
\lim q_{j \downarrow 0} \frac{\partial}{\partial q_{j}} u_{i}\left(q_{0}, \ldots, q_{N}\right)=+\infty, \lim q_{j \downarrow \infty} \frac{\partial}{\partial q_{j}} u_{i}\left(q_{0}, \ldots, q_{N}\right)=0 .
$$

The numeraire commodity is assumed to be already traded on the market by time $\mathrm{t}-1$. It can be thought of as some nonperishable foodstuff.

Firms produce $\mathrm{N}$ distinct products and are hence divided into $\mathrm{N}$ sectors. Each sector $j$ consists of $L_{j}$ identical firms, where $L_{j} \in[1,+\infty)$. When $L_{j}=$ 1 , sector $j$ is a monopoly; when $L_{j}$ is large enough (approaching infinity), sector $j$ is competitive; when $L_{j}$ is between 1 and infinity, it can have different degrees of competitiveness (Tirole, 1988). This also implies that all firms within a sector has the same cost function. At time $t-1, k$ sectors are public (denoted by sector $1, \ldots \mathrm{k}$ ), and $\mathrm{N}-\mathrm{k}+1$ sectors are private (denoted by sectors $\mathrm{k}+1$, $k+2, \ldots, N, 0$ ). In each period the Public Servant can choose to privatize one or more sectors. At time $t$, the Public Servant decides whether to continue privatizing, and which sector(s) to privatize. Without loss of generality, we assume sector $\mathrm{k}$ is picked. We can then study the characteristics of $\mathrm{k}$ and the influence of its privatization on the changes in consumer welfare.

Assume that a firm lj in public sector $j$ fulfills quota $\bar{Q}_{\mathbf{l j}}$ imposed by the Public Servant, and sells its output at a fixed price $\bar{P}_{j}$, which is below the market-clearing price. This assumption reflects a basic feature of centrally planned economies, where prices are fixed for historical reasons and reflect neither cost nor market demand. ${ }^{2}$ Therefore, the total output of sector $j$ is $\overline{\mathrm{Q}}_{\mathrm{j}}=\overline{\mathrm{Q}}_{\mathrm{ij}} \mathrm{L}_{\mathrm{j}}$. For simplicity, assume the population in the economy is fixed. Therefore, we can assume that $\bar{Q}_{j}$ and $\bar{Q}_{1 j}$ are fixed as long as sector $j$ remains public, since the quota is decided by rationing over the total population. Let $\mathrm{C}_{\mathrm{j}}(\cdot)$ be the cost function of any firm $\mathrm{lj}$ in sector $\mathrm{j}$, since they are all identical. The following assumption simplifies the definition of the market power index defined and used in Section 3.

Assumption 2. All firms in the same sector have the same cost function: $\mathrm{Cj}: R_{+}^{1} \rightarrow R_{+}^{1}$ is differentiable and monotonic, for $j=0,1, \ldots, N$. 
This assumption simplifies the definition of the market power index. After sector $\mathrm{j}$ is privatized, firm lj's objective becomes profit maximization. Let $\pi_{\mathrm{lj}}$ be the firm's profit function. It chooses the optimal output $\mathrm{Q}_{\mathrm{lj}}$ and sells it at the market-clearing price $P_{j}$.

Let $P_{j}\left(Q_{1}, \ldots, Q_{N}\right)$ be sector $j$ 's inverse demand function. To ensure the existence of a Cournot equilibrium (Novshek, 1985), we need the following assumption.

Assumption 3. $\mathrm{P}_{\mathrm{j}}(\overrightarrow{\mathrm{Q}})$ is twice continuously differentiable, monotonic, and satisfies $\frac{\partial \mathrm{P}_{\mathrm{j}}(\overrightarrow{\mathrm{Q}})}{\partial \mathrm{Q}_{\mathrm{j}}}+\mathrm{Q}_{\mathrm{j}} \frac{\partial^{2} \mathrm{P}_{\mathrm{j}}(\overrightarrow{\mathrm{Q}})}{\partial \mathrm{Q}_{\mathrm{j}}^{2}} \leq 0$, which requires the inverse demand function to be concave.

Note that the cost function of firm $\mathrm{lj}$ does not change before or after privatization. Here we implicitly assume that technology does not change. What is changed is the production quantity and price, which is adjusted for the purpose of profit maximization. This implies that the objective functions of the firms change after privatization, but any efficiency gain occurs after the transition period. $^{3}$

In order to simplify the structure in the later part of the model, we assume that none of the products of the $\mathrm{N}$ sectors are substitutes for each other. They can be either independent or complements. Another way to think about this assumption is to group all the substitutes in the economy in the same sector and simplify them into one product by using marginal rates of substitution.

Assumption 4. $\frac{\partial \mathrm{Q}_{\mathrm{i}}}{\partial \mathrm{P}_{\mathbf{j}}} \leq 0, \forall \mathbf{i} \neq \mathbf{j}$.

This is equivalent to saying that the cross elasticity of any two products $\varepsilon_{\mathrm{ij}}=$ $-\frac{\partial q_{i}}{\partial P_{j}} \frac{P_{j}}{q_{i}} \geq 0, \forall i \neq j, i, j=1,2, \ldots, n$, which implies that the consumers' utility functions need to satisfy the following condition: $\frac{\partial^{2} u_{i}(\vec{q})}{\partial q_{i} \partial q_{l}} \leq 0, \forall l=$ $1, \ldots, \mathrm{N}$.

We consider two types of Public Servant. Either type knows the distribution of consumers' utility functions $\mathrm{s}^{4}$ and of share ownership, and the matrices of supply and demand elasticities of every product. The reason for this assumption is to see what would be his best policy if he has enough information. At any given time $t$, he makes three decisions - whether to continue privatizing, which sector to privatize, and how to compensate the consumers. In order to concentrate on the characteristics of the transition period, we neglect some other important functions of the government, such as public good provision, 
and assume that the Public Servant's only functions are privatization and compensation. We use the parameter $d$ to characterize the political institutions, where $d$ is the percentage of consumers he needs to satisfy in order to stay in office.

\section{Analysis of the model}

\subsection{The firm's problem}

Public firm lj in sector $\mathrm{j}$ is given the quota $\overline{\mathrm{Q}}_{\mathrm{lj}}$. Assume each firm is given the same quota, i.e., $\overline{\mathrm{Q}}_{\mathrm{lj}}=\overline{\mathrm{Q}}_{\mathrm{kj}}$, for all $\mathrm{k}$, 1. Suppose it can fulfill the quota and sell its output at the fixed price $\overline{\mathrm{P}}_{\mathrm{j}}$. Then it will provide revenue (or require subsidy) in the amount $B_{1 j}$, where

$$
\mathrm{B}_{\mathrm{lj}}=\overline{\mathrm{P}}_{\mathrm{j}} \overline{\mathrm{Q}}_{\mathrm{lj}}-\mathrm{C}_{\mathrm{j}}\left(\overline{\mathrm{Q}}_{\mathrm{lj}}\right) \text {. }
$$

After the firm is privatized, it becomes a profit maximizer. It chooses its optimal output $\mathrm{Q}_{\mathrm{jj}}$ to maximize its profit. The price of product $\mathrm{j}$ is determined by the total output of the sector, which depends on the decisions of the other identical firms in the same sector and the total output of other sectors. Note that by Assumption 1, consumers all have quasilinear utility functions, so the inverse demand functions exist. We use Cournot equilibrium analysis for the private firms' decisions.

Firm lj chooses the optimal output $\mathrm{Q}_{\mathrm{lj}}$ in order to

$$
\max _{Q_{1 j}} P_{j}\left(Q_{1}, \ldots, Q_{N}\right) Q_{1 j}-C_{j}\left(Q_{1 j}\right) .
$$

From Assumption 2, the second order condition for the above maximization problem is satisfied, so we only need to look at the first order condition, which is,

$$
P_{j}+Q_{1 j}\left[\frac{\partial P_{j}}{\partial Q_{j}}+\underset{h \neq j}{\Sigma} \frac{\partial P_{j}(\vec{Q})}{\partial Q_{h}} \frac{\partial Q_{h}}{\partial Q_{j}}\right]-M_{j}=0 .
$$

Let $\mathrm{MC}_{\mathrm{j}}$ be the marginal cost of firms in sector $\mathrm{j}$. Rearranging terms we get

$$
\frac{\mathrm{P}_{\mathrm{j}}(\overrightarrow{\mathrm{Q}})-\mathrm{MC}_{\mathrm{j}}}{\mathrm{P}_{\mathrm{j}}(\overrightarrow{\mathrm{Q}})}=\frac{1}{\mathrm{~L}_{\mathrm{j}}}\left[\frac{1}{\varepsilon_{\mathrm{jj}}}+\sum_{\mathrm{h} \neq \mathrm{j}} \frac{1}{\varepsilon_{\mathrm{jh}}}\right]=\frac{1}{\mathrm{~L}_{\mathrm{j}}} \sum_{\mathrm{h}=1}^{\mathrm{N}} \frac{1}{\varepsilon_{\mathrm{jh}}} \equiv \alpha_{\mathrm{j}}
$$

where $\varepsilon_{\mathrm{jj}}$ is the own elasticity of demand at $\mathrm{Q}_{\mathrm{j}}$, and $\varepsilon_{\mathrm{jh}}$ is the cross elasticity of demand between product $j$ and product $h$. Since all firms of the same sector are identical, namely, they all have the same cost functions, the market share of firm $1 j$ equals the inverse of the number of firms in sector $j$, i.e., $\frac{Q_{1 j}}{Q_{j}}=$ 
$\frac{1}{\mathrm{~L}_{\mathrm{j}}}$. Call $\alpha_{\mathrm{j}}$ firm lj's market power index, which also characterizes sector $\mathrm{j}$ 's

$\mathrm{L}_{\mathrm{j}}$ market power. Alternatively, the above equation can be expressed as $P_{j}=\frac{M C_{j}}{1-\alpha_{j}}$, which will be used later.

Note that the market power index is quite general with regard to the degree of competitiveness in a sector. When $L_{j}=1$, the above formula becomes the monopoly pricing formula. On the other hand, if $L_{j} \rightarrow \infty$, the equilibrium converges to the competitive equilibrium (Tirole, 1988). Therefore, the market power index shows how much a sector can raise the price of its product above its marginal cost. It is inversely related to the number of firms in the sector and the elasticities of demand of the product.

\subsection{The consumer's problem}

In order to study the effects of the privatization of a certain sector, say $\mathbf{k}$, on the change of a consumer's utility, we study his maximization problem in two arbitrarily chosen contiguous time periods, $t-1$ and $t$.

At time $\mathrm{t}-1$, sectors $1, \ldots, \mathrm{k}$ are in the public sector, fulfilling quotas; sectors $0, \mathrm{k}+1, \ldots, \mathrm{N}$ are in the private sector, maximizing profits. Consumer i's rationed quantities of products 1 through $\mathrm{k}$ are $\overline{\mathrm{q}}_{1}, \ldots, \overline{\mathrm{q}}_{\mathrm{k}}$, which are allocated equally to everybody in the economy. In reality, the allocations vary from person to person according to age, sex and other personal characteristics. Here, for simplicity of analysis, and also because we can not distinguish among individual consumers, we assume an equal allocation.

At time $t$, if another sector, say, sector $k$, is privatized, consumer $i$ is given compensation $\mathrm{T}$ for the price increase in product $\mathrm{k}$ and the price changes in the other private sectors. At the same time, he can buy shares in the newly privatized sector. So he chooses $\mathrm{q}_{\mathrm{ik}}^{\mathrm{t}}, \ldots . \mathrm{q}_{\mathrm{iN}}^{\mathrm{t}}, \mathrm{q}_{\mathrm{i} 0}^{\mathrm{t}}$ in order to

$$
\begin{aligned}
& \max _{\left(q_{i j}^{t}\right\}_{j=0, k}^{N}} u_{i}\left(\bar{q}_{1}, \ldots, \bar{q}_{k-1}, q_{i k}^{t}, \ldots, q_{i N}^{t}\right)+q_{i 0}^{t} \\
& \text { s.t. } \sum_{j=0, k}^{N} p_{j}^{t} q_{i j}^{t}=y_{i}+\sum_{j=k}^{N} \theta_{i j}\left(1-\tau_{j}\right) \pi_{j}^{t}-\theta_{i k} S_{k}-\sum_{j=1}^{k-1} \bar{P}_{j} \bar{q}_{j}+T \equiv y_{i}^{t},
\end{aligned}
$$

where $S_{k}$ is the total revenue from the sale of sector $k, \tau_{j}$ is the tax rate of sector $\mathrm{j}$, and $\theta_{\mathrm{ij}}$ is consumer $\mathrm{i}$ 's proportion of shares in sector $\mathrm{j}$. From the budget constraint, consumer i's income comes from two sources: his exogenously given income $y_{i}$, which can be interpreted as wage and other personal endowments, and his share of the after tax profit from the private sector, 
$\Sigma_{\mathrm{j}=\mathrm{k}}^{\mathrm{N}} \theta_{\mathrm{ij}}\left(1-\tau_{\mathrm{j}}\right) \pi_{\mathrm{j}}^{\mathrm{t}}$. His effective income, $\mathrm{y}_{\mathrm{i}}^{\mathrm{t}}$, with which he can choose his consumption bundle among products produced in the private sector, is total income less the expenditure on rationed products.

Therefore, his indirect utility function is

$$
\mathrm{v}_{\mathrm{i}}\left(\overrightarrow{\mathrm{P}}^{\mathrm{t}}, \mathrm{y}_{\mathrm{i}}^{\mathrm{t}}\right)=\varphi_{\mathrm{i}}\left(\overrightarrow{\mathrm{P}}^{\mathrm{t}}\right)+\mathrm{y}_{\mathrm{i}}^{\mathrm{t}},
$$

where $\varphi_{i}\left(\overrightarrow{\mathrm{P}}^{\mathrm{t}}\right)=\mu_{\mathrm{i}}\left(\overline{\mathrm{q}}_{1}, \ldots, \overline{\mathrm{q}}_{\mathrm{k}-1}, \mathrm{q}_{\mathrm{ik}}^{\mathrm{t}}\left(\overrightarrow{\mathrm{P}}^{\mathrm{t}}\right), \ldots \mathrm{q}_{\mathrm{iN}}^{\mathrm{t}}\left(\overrightarrow{\mathrm{P}}^{\mathrm{t}}\right)\right)-\sum_{\mathrm{j}=\mathrm{k}}^{\mathrm{N}} \mathrm{P}_{\mathrm{j}}^{\mathrm{t}} \mathrm{q}_{\mathrm{ij}}^{\mathrm{t}}\left(\overrightarrow{\mathrm{P}}^{\mathrm{t}}\right)$, and where $\overrightarrow{\mathbf{P}}^{t}$ is the shorthand for the vector of all prices at time $t$. Since consumer $i$ has quasi-linear utility function, his indirect utility function can be written in two parts, with effective income separate from $\varphi_{i}\left(\overrightarrow{\mathrm{P}}^{t}\right)$, and the demand function is independent of income.

Consumer i's indirect utility function at time $t-1$ is obtained similarly. Since consumer $i$ has one degree less freedom and less purchasing power at time $t-1$ compared to time $t$, his effective income at time $t-1$ is

$$
y_{i}^{t-1} \equiv y_{i}+\sum_{j=k+1}^{N} \theta_{i j}\left(1-\tau_{j}\right) \pi_{j}^{t-1}-\sum_{j=1}^{k} \vec{P}_{j} \bar{q}_{j} .
$$

Then his indirect utility function at time $t-1$ is

$$
\mathrm{v}_{\mathrm{i}}\left(\overrightarrow{\mathrm{P}}^{\mathrm{t}-1}, \mathrm{y}_{\mathrm{i}}^{\mathrm{t}-1}\right)=\varphi_{\mathrm{i}}\left(\overrightarrow{\mathrm{P}}^{\mathrm{t}-1}\right)+\mathrm{y}_{\mathrm{i}}^{\mathrm{t}-1},
$$

where

$$
\begin{aligned}
& \varphi_{i}\left(\overrightarrow{\mathrm{P}}^{\mathrm{t}-1}\right)=\mu_{\mathrm{i}}\left(\overline{\mathrm{q}}_{1}, \ldots, \overline{\mathrm{q}}_{\mathrm{k}}, \mathrm{q}_{\mathrm{ik}+1}^{\mathrm{t}-1}\left(\overrightarrow{\mathrm{P}}^{\mathrm{t}-1}\right), \ldots, \mathrm{q}_{\mathrm{iN}}^{\mathrm{t}-1}\left(\overrightarrow{\mathrm{P}}^{\mathrm{t}-1}\right)\right)- \\
& \Sigma_{\mathrm{j}=0, \mathrm{k}+1}^{\mathrm{N}} \mathrm{P}_{\mathrm{j}}^{\mathrm{t}-1} \mathrm{q}_{\mathrm{ij}}^{\mathrm{t}}\left(\overrightarrow{\mathrm{P}}^{\mathrm{t}-1}\right) .
\end{aligned}
$$

We can calculate the minimal amount of compensation for consumer i necessary to keep him on the same indifference curve as he was before sector $\mathrm{k}$ is privatized by equating his indirect utility function at time $t$ to that at $t-1$,

$$
\begin{aligned}
& v_{i}\left(\vec{P}^{t}, y_{i}^{t}\right)=v_{i}\left(\vec{P}^{t-1}, y_{i}^{t-1}\right), \text { i.e., } \\
& \varphi_{i}\left(\vec{P}^{t}\right)+y_{i}^{t}=\varphi_{i}\left(\vec{P}^{t-1}\right)+y_{i}^{t-1},
\end{aligned}
$$

Plugging in the definition of $y_{i}^{t}$ and $y_{i}^{t-1}$ from Eqn (2) and (3), and rearraning terms we get the individual consumer's minimal compensation,

$$
\begin{aligned}
& \mathrm{T}_{\mathrm{i}}^{*}=\varphi_{\mathrm{i}}\left(\overrightarrow{\mathrm{P}}^{\mathrm{t}-1}\right)-\varphi_{\mathrm{i}}\left(\overrightarrow{\mathrm{P}}^{\mathrm{t}}\right)+\sum_{\mathrm{j}=\mathrm{k}+1}^{\mathrm{N}} \theta_{\mathrm{ij}}\left(1-\tau_{\mathrm{j}}\right)\left(\pi_{\mathrm{j}}^{\mathrm{t}-1}-\pi_{\mathrm{j}}^{\mathrm{t}}\right)+\theta_{\mathrm{ik}}\left[\mathrm{S}_{\mathrm{k}}-\left(1-\tau_{\mathrm{k}}\right) \pi_{\mathrm{k}}^{\mathrm{t}}\right]- \\
& \overrightarrow{\mathrm{P}}_{\mathrm{k}} \overline{\mathrm{q}}_{\mathrm{k}} .
\end{aligned}
$$


The first two terms, the price effect, are the change of his indirect utility due to price changes; the next two terms, the profit effect, show the consumer's income changes due to the changes in his after tax profit shares, where $\Sigma_{j=k+1}^{N} \theta_{i j}\left(1-\tau_{j}\right)\left(\pi_{j}^{t-1}-\pi_{j}^{t}\right)$ is the total change in i's shares of after tax profits in the old private sectors as a result of privatizing sector $\mathrm{k}$, and $\theta_{i k}\left[S_{k}-\left(1-\tau_{k}\right) \pi_{k}^{t}\right]$ is his total payment for his shares in the newly privatized sector less his share of the after-tax profit in this sector. Note that the profit effect can be either positive or negative. So are the individual consumers' minimal compensations. This is an important expression in the later analysis of the Public Servant's problem.

Figure 1 shows the consumer's consumption before and after privatization in a simple two-good economy. At time $t-1$, sector 2 is private, while sector 1 is public. Since $\bar{q}_{1}$ is the rationed amount, the consumer's consumption bundle $\left(\overline{\mathrm{q}}_{1}, \mathrm{q}_{2}^{\mathrm{t}-1}\right)$ usually is not the tangency point. At time $t$, sector 1 is privatized. The price of product 1 goes up to the market clearing price $P_{1}$, and the price of product 2 also changes. With the new price ratio and effective income, the consumer maximizes his utility subject to his budget constraint. For some consumers, the new consumption bundle can lie on a higher indifference curve; for others, it can lie on a lower indifference curve. The minimal compensation, $\mathrm{T}^{*}$, shows the amount of transfer needed to get the consumer to the tangent point consumption bundle, $\left(\mathrm{q}_{1}^{\mathrm{t}}, \mathrm{q}_{2}^{\mathrm{t}}\right)$, on the previous indifference curve. Note that it could be positive, zero or negative.

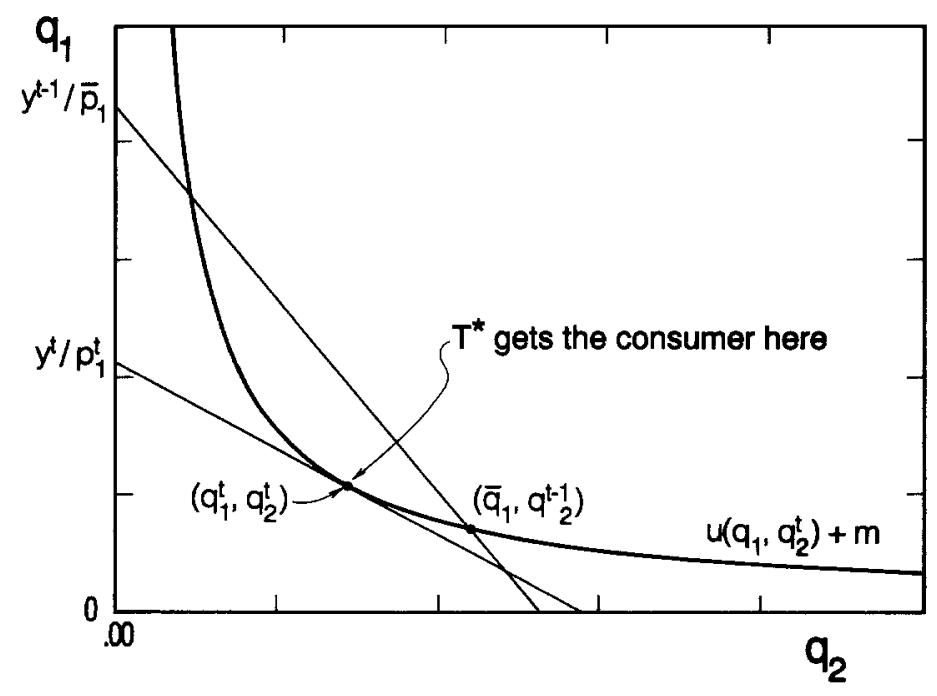

Figure 1. Consumption before and after privatization of Sector 1. 


\subsection{The Public Servant's problem}

The Public Servant is a highly simplified representation of the government. At any given time $t$, he decides whether to continue privatizing, and, if yes, what sector(s) to privatize and how to compensate the consumers. Assume at time $t$, his budget comes from three sources:

(1) Revenue and subsidies from the public sectors, $\Sigma_{j=1}^{k-1} B_{j}$;

(2) Revenue from the sale of the public sector $\mathrm{k}, \mathrm{S}_{\mathrm{k}}$;

(3) Taxes from the private sectors, $\Sigma_{\mathrm{j}=\mathrm{k}}^{\mathrm{N}} \tau_{\mathrm{j}} \pi_{\mathrm{j}}^{\mathrm{j}}$.

It would be interesting to understand the details of the sale process. But since it depends on the bargaining power of the seller and the buyers, the future profitability of the firms and a number of other political considerations, we do not study these in this paper. Assume that the sale revenue has the following relationship with the after tax profit, $S_{k}=\left(1+\varepsilon_{k}\right)\left(1-\tau_{k}\right) \pi_{k}^{t}$, where $\varepsilon_{k} \in R^{1}$ represents the difference between the sale amount and the actual after tax profit due to the bargaining power of the buyers and seller, political considerations or other factors.

One type of Public Servant, the Bureaucrat, has the objective function of maximizing the surplus budget, i.e., total budget less total consumer compensation, subject to the constraint of staying in office. The surplus can be used to build up the Bureaucracy, or on personal gratification, if he is a corrupt bureaucrat. ${ }^{5}$ This objective function can be justified under a range of circumstances (Niskanen, 1971). In a society with elections, suppose that consumers/ voters use a retrospective voting rule, i.e., they will vote for the Bureaucrat if they occupy the same or a higher utility curve in this period as in the last period, and vote against him if they are on a lower utility curve (Fiorina, 1981). Denote the proportion of votes he has to get to stay in office as $d$. Note that different democratic systems can have different $d$ 's. In a society without elections, the Bureaucrat also needs to satisfy a certain percentage of consumers to be able to stay in office, though this $d$ could be much lower than the one in a democratic society. For example, suppose that consumers in a society without elections judge the Bureaucrat's policy in a similar retrospective way as those in a democratic society, and they can throw the Bureaucrat out of the office by revolt or other means, if the percentage of dissatisfied consumers exceeds $1-$ $d$. Therefore, the Bureaucrat's constraint is to satisfy at least $d$ percent of the consumers to stay in office.

Assume that the Public Servant knows the distribution of the consumers' utility functions, but does not know the utility functions of individual consumers. In each period, therefore, he compensates everybody the same amount. ${ }^{6}$ Depending on their utility functions, some consumers will be better 
off and some will be worse off after the privatization and the compensation than they were before.

To formalize the problem, let the Bureaucrat choose the sector and the level of consumer compensation to

$$
\begin{aligned}
& \max \Sigma_{j=1}^{k} B_{j}+\Sigma_{j=k+1}^{N} \tau_{j} \pi_{j}^{t}+\left[-B_{k}+S_{k}+\tau_{k} \pi_{k}^{t}\right]-I \cdot T \\
& \text { s.t. } \\
& \qquad \frac{1}{I}\left|\mathrm{i}: T \geq T_{i}^{*}\right| \geq d,
\end{aligned}
$$

where $\mathrm{I} \cdot \mathrm{T}$ is the total transfers, and the constraint means that at least $d$ of the voters are content with the level of compensation offered by the government.

For comparison with the behavior of the Bureaucrat, we model another kind of Public Servant, the Populist, whose objective function is to maximize popularity or consumer welfare, subject to a balanced budget,

$\max$

$$
\mathrm{W}^{\mathrm{t}}=\Sigma_{\mathrm{i}} \mathrm{v}_{\mathrm{i}}^{\mathrm{t}}
$$

$$
\text { s.t. } \Sigma_{j=1}^{k} B_{j}+\Sigma_{j=k+1}^{N} \tau_{j} \pi_{j}^{t}+\left[-B_{k}+S_{k}+\tau_{k} \pi_{k}^{t}\right]=I \cdot T
$$

In the next section, we will analyse the decisions of both types of Public Servant and compare their optimal behavior.

\section{Main results and discussion}

To get the final results about the Public Servant's optimal privatization policy, the first step is to analyse how an individual consumer's minimal compensation changes with the different characteristics of a sector. Since the Public Servant does not know each individual's utility function, but knows the distribution of their utility functions, the second step is to get the minimal aggregate compensation from the distribution of utility functions and the political constraint, $d$. The third step is to derive the main results about the Public Servant's optimal privatization policy. Then we show some results on the effects of political institutions on the privatization process.

\subsection{Individual consumer's minimal compensation}

In order to study the Public Servant's decision, we need to know how an individual consumer's minimal compensation changes with the characteristics of sector $\mathrm{k}, \alpha_{\mathrm{k}}$. 
Proposition 1. When a sector $\mathrm{k}$ is privatized, and consumer i's share in sector $\mathrm{k}$ is sufficiently small, then other things being constant, the minimal individual compensation increases with an increase in $\mathrm{P}_{\mathrm{k}}^{\mathrm{t}}$, and with an increase in the market power of sector $\mathrm{k}$, and vice versa, I.e.,

$$
\begin{gathered}
\frac{\partial \mathrm{T}_{\mathrm{i}}^{*}}{\partial \mathrm{P}_{\mathrm{k}}^{\mathrm{t}}}, \frac{\partial \mathrm{T}_{\mathrm{i}}^{*}}{\partial \alpha_{\mathrm{k}}}\left\{\begin{array}{l}
\geq 0 \text { if } \epsilon_{\mathrm{k}} \frac{\partial \pi_{\mathrm{k}}^{\mathrm{t}}}{\partial \mathrm{P}_{\mathrm{k}}^{\mathrm{t}}}<0 \text { and } \theta_{\mathrm{ik}} \leq \mathrm{A}_{\mathrm{i}}, \text { or } \epsilon_{\mathrm{k}} \frac{\partial \pi_{\mathrm{k}}^{\mathrm{t}}}{\partial \mathrm{P}_{\mathrm{k}}^{\mathrm{t}}} \geq 0 ; \\
<0 \text { if } \epsilon_{\mathrm{k}} \frac{\partial \pi_{\mathrm{k}}^{\mathrm{t}}}{\partial \mathrm{P}_{\mathrm{k}}^{\mathrm{t}}}<0 \text { and } \theta_{\mathrm{ik}}>\mathrm{A}_{\mathrm{i}} ; \text { where }
\end{array}\right. \\
\mathrm{A}_{\mathrm{i}}=\frac{\frac{\partial \varphi_{\mathrm{i}}\left(\mathrm{P}^{\mathrm{t}}\right)}{\partial \mathrm{P}_{\mathrm{k}}^{\mathrm{t}}}+\Sigma_{\mathrm{j}=\mathrm{k}+1}^{\mathrm{N}} \theta_{\mathrm{ij}}\left(1-\tau_{\mathrm{j}}\right) \frac{\partial \pi_{\mathrm{j}}^{\mathrm{t}}}{\partial \mathrm{P}_{\mathrm{k}}^{\mathrm{t}}}}{\epsilon_{\mathrm{k}}\left(1-\tau_{\mathrm{k}}\right) \frac{\partial \pi_{\mathrm{k}}^{\mathrm{t}}}{\partial \mathrm{P}_{\mathrm{k}}^{\mathrm{t}}}}
\end{gathered}
$$

Proof. See Appendix. ${ }^{7}$

Intuitively, for a small shareholder or for somebody who does not hold any shares in the newly privatized sector, the price effect dominates the profit effect - he mainly suffers from the price increase as a consumer; for a large shareholder, however, the profit effect dominates the price effect.

Figure 2 illustrates Proposition 1 with a simple computer simulation. The economy consists of 100 consumers and two goods. Consumer i's utility function takes the form of $u_{i}=a_{i} \sqrt{q 1}+\left(1-a_{i}\right) \sqrt{q 2}$, where the indices $a_{i} \in[0,1]$ are generated randomly by the computer. At time $t-1$, both sector 1 and 2 are public. We normalize $\overline{\mathrm{P}}_{1}=\overline{\mathrm{P}}_{2}=\overline{\mathrm{q}}_{2}=1$. At time $\mathrm{t}$, sector 2 , is privatized, but sector 1 is still public. Let the tax rate be 0.3 , and $\epsilon_{2}$ be 0 . Let sector 2 have a cubic cost function, $C_{2}=.04 q_{3}^{2}-.9 q_{2}^{2}+10 q+5$. For a randomly picked consumer $\mathrm{i}$, we give him different proportion of shares in sector $\mathrm{k}$, and plot out how his minimal compensation, $T_{i}^{*}$, changes with the change in $P_{k}$, when his proportion of shares, $\theta=0,0.1,0.3,0.5$. We can see that when $\theta=0,0.1$, his minimal compensation increases with an increase in $P_{k}$; when $\theta=0.3$, the cutpoint, the graph goes to the other direction from $P_{k}=2$; when $\theta=0.5$, this large shareholder's minimal compensation decreases with an increase in $\mathbf{P}_{\mathbf{k}}$. Note that this is only a 100 -consumer economy. In a large economy, the threshold should be much smaller. 

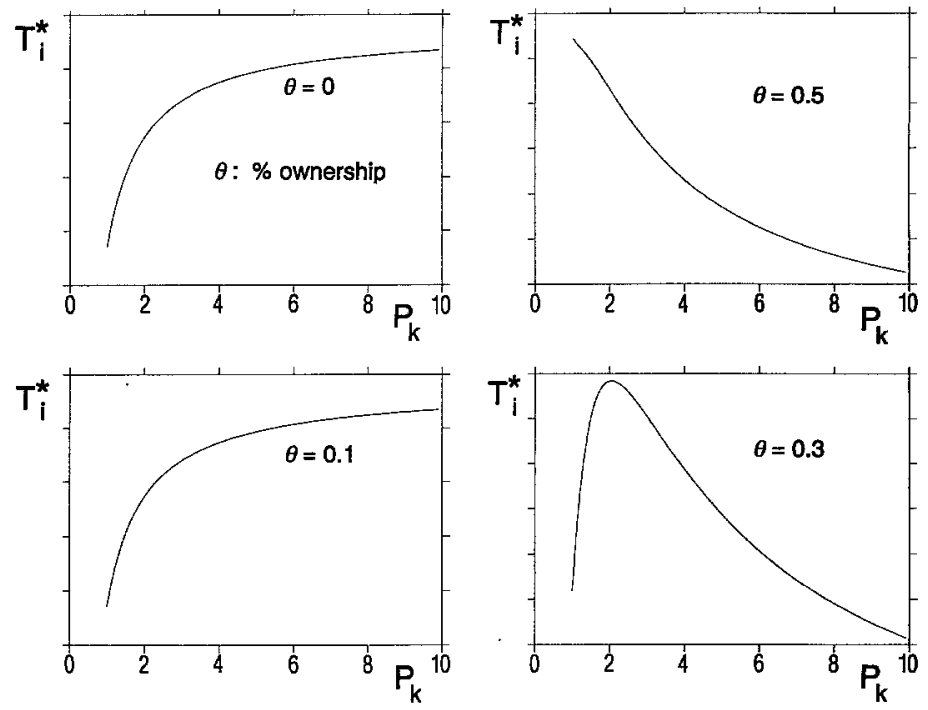

Figure 2. Minimal individual compensation.

\subsection{Minimal aggregate compensation}

Since the Public Servant does not know each individual's utility functions and shares, he can only make his decision from the aggregate behavior of the individual's minimal compensation. In what follows, we derive the minimal aggregate compensation to all individuals.

Recall the form of the minimal individual compensation, $T_{i}^{*}$,

$$
\mathrm{T}_{\mathrm{i}}^{*}=\varphi_{\mathrm{i}}\left(\overrightarrow{\mathrm{P}}^{\mathrm{t}-1}\right)-\varphi_{\mathrm{i}}\left(\overrightarrow{\mathrm{P}}^{\mathrm{t}}\right)+\sum_{\mathrm{j}=\mathrm{k}+1}^{\mathrm{N}} \theta_{\mathrm{ij}}\left(1-\tau_{\mathrm{j}}\right)\left(\pi_{\mathrm{j}}^{\mathrm{t}-1}-\pi_{\mathrm{j}}^{\mathrm{t}}\right)+\theta_{\mathrm{ik}} \epsilon_{\mathrm{k}}\left(1-\tau_{\mathrm{k}}\right) \pi_{\mathrm{k}}^{\mathrm{t}}-\overline{\mathrm{P}}_{\mathrm{k}} \overline{\mathrm{q}}_{\mathrm{k}} .
$$

Note that there are two kinds of distributions in the above expression, the indirect utility function $\phi(\cdot)$ and the consumer's proportion of shares in a private sector, $\theta_{\cdot j}$. So in order to know the distribution of $T_{i}^{*}$, we need to know the distributions of $\phi_{\mathrm{i}}\left(\overrightarrow{\mathrm{P}}^{\mathrm{t}-1}\right)-\phi_{\mathrm{i}}\left(\overrightarrow{\mathrm{P}}^{\mathrm{t}}\right)$ and $\theta_{\cdot \mathrm{j}}$.

Different individuals usually have different utility functions. Let $\mathcal{F}$ be all possible functional forms of $\phi(\cdot)$, and let $\Phi$ be the admissible set of $\mathcal{F}$, i.e., $\Phi \subset \mathcal{F}: \mathbb{R}^{\mathrm{N}} \rightarrow \mathbb{R}$. We can label the indirect utility functions in $\Phi$ by $\omega$. Let the index set $\Omega$ be a subset of the real line, i.e., $\omega \in \Omega \subset \mathrm{R}$. We assume that $\phi(\cdot, \omega)$ depends continuously on index $\omega$, and that $\frac{\partial \phi(\cdot, \omega)}{\partial \omega}>0 . \omega$ has cumulative distribution function $M(\omega)$.

Let $\theta_{._{j}} \sim F_{j}, j=k, k+1, \ldots, N$. Let the joint distribution of $\theta_{k}, \ldots, \theta_{N}$ be 
$\mathrm{F}(\theta)^{\mathrm{n}-\mathrm{k}-1}$, where $\theta \in \Theta$, and $\Theta$ is the admissible set of $\theta_{. \mathrm{j}}$. We employ the following notation: $\vec{\beta}=\left(b_{k}, b_{k+1}, \ldots, b_{N}\right)$, where the $b_{j}$ 's are the coefficients of the $\theta_{. j}$ 's; $c \equiv \overline{\mathrm{P}}_{\mathrm{k}} \overline{\mathrm{q}}_{\mathrm{k}}$, which is a constant because it is the expenditure on the rationed allotment of product $k$. For simplicity of calculation, assume that $\omega$ and $\theta_{j}$ are independent of each other. Suppose $T_{i}^{*} \sim G(\cdot, \vec{\beta})$, then for any given level of compensation $T$, the cumulative distribution function of $T_{i}^{*}$, i.e., the percentage of consumers for which $T_{i}^{*} \leq T$, is

$$
\mathrm{G}(\mathrm{T}, \vec{\beta})=\int \ldots \int_{\Theta}\left[\int_{\left\{\omega \in \Omega: \phi\left(\overrightarrow{\mathrm{P}}^{\mathrm{t}}-1, \omega\right)-\phi\left(\overrightarrow{\mathrm{P}}^{\mathrm{t}}, \omega\right)+\vec{\beta} \vec{\theta}-\mathrm{c} \leq \mathrm{T}\right\}} \mathrm{dM}(\omega)\right] \mathrm{dF}(\theta)^{\mathrm{n}-\mathrm{k}+1} .
$$

It follows that the cumulative distribution of $\mathrm{T}_{\mathrm{i}}^{*}$ can be expressed in terms of the distribution of $\omega$ and $\vec{\theta}$. And this facilitates our method of solving the Public Servant's problem.

In the Bureaucrat's problem, the constraint, (B2), is equivalent to $G(T, \vec{\beta})$ $\geq \mathrm{d}$. Then his constrained maximization problem, (B1) and (B2), can be converted into one of unconstrained maximization by finding the minimal $T$, $\mathrm{T}_{\min }$, to keep him in office. Therefore, he chooses the public sector $\mathrm{k}$ to

$$
\max \sum_{j=1}^{k} B_{j}+\sum_{j=k+1}^{N} \tau_{j} \pi_{j}^{t}+\left[-B_{k}+S_{k}+\tau_{k} \pi_{k}^{t}\right]-I \cdot T_{\min },
$$

where $T_{\min }$ is the solution to $G\left(T_{\min }, \vec{\beta}\right)=d$. We call $T_{\min }$ the minimal aggregate compensation in a transition economy.

Figure 3 illustrate the concept of the minimal aggregate compensation by using the same economy as in Figure 2, by calculating the minimal individual compensation for all 100 consumers and plotting out the cumulative distribution function. Then for any given level of $d$, the proportion of consumers to be left not worse off by the privatization of sector $k$, there is corresponding $\mathrm{T}_{\min }$, so that at least $\mathrm{d}$ percent of the consumers are better off.

The following proposition characterizes the properties of $\mathrm{T}_{\min }-$ how it changes with the changes in the underlying parameters.

Proposition 2. In a large population, the minimal aggregate compensation, $\mathrm{T}_{\min }$, increases with an increase in the market power of sector $\mathrm{k}, \alpha_{\mathrm{k}}$, i.e.,

$$
\frac{\partial \mathrm{T}_{\min }}{\partial a_{\mathrm{k}}} \geq 0
$$

(1) if $\epsilon_{\mathrm{k}} \frac{\partial \pi_{\mathrm{k}}^{\mathrm{t}}}{\partial \mathrm{P}_{\mathrm{k}}^{\mathrm{t}}} \geq 0$, or 


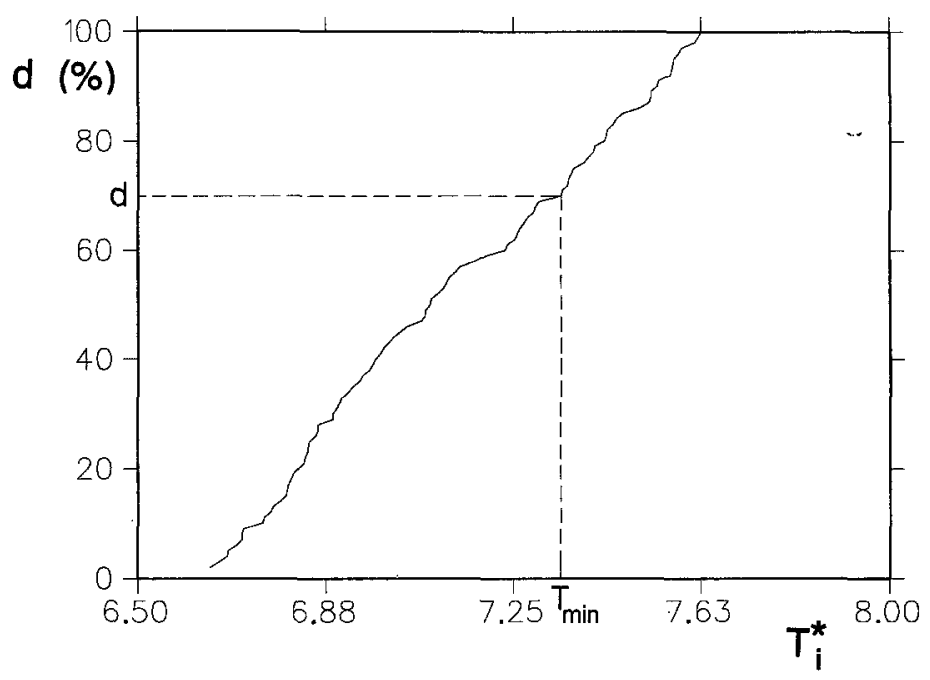

Figure 3. Minimal aggregate compensation.

(2) if $\epsilon_{\mathrm{k}} \frac{\partial \pi_{\mathrm{k}}^{\mathrm{t}}}{\partial \mathrm{P}_{\mathrm{k}}^{\mathrm{t}}}<0$ and $\operatorname{Prob}\left\{\theta_{\mathrm{k}} \leq \underline{\mathrm{A}}\right\}=1$, which holds in a large population; where

$$
\underline{A}=\frac{\frac{\partial \varphi\left(\overrightarrow{\mathrm{P}}^{\mathrm{t}}, \bar{\omega}\right)}{\partial \mathrm{P}_{\mathrm{k}}^{\mathrm{t}}}}{\epsilon_{\mathrm{k}}\left(1-\tau_{\mathrm{k}}\right) \frac{\partial \pi_{\mathrm{k}}^{\mathrm{t}}}{\partial \mathrm{P}_{\mathrm{k}}^{\mathrm{t}}}}
$$

The intuition behind this result is quite clear. In a large population most people will own a very small percentage of the total shares, a percentage that approximates zero. It follows from Proposition 1 that for small shareholders, whose price effect dominates profit effect, their minimal individual compensation increases as the price increases. Therefore, on the aggregate level, the minimal aggregate compensation, $\mathrm{T}_{\min }$, increases with an increase in the market power of sector $\mathrm{k}, \alpha_{\mathrm{k}}$.

\subsection{The Public Servant's optimal behavior}

This section contains two main propositions of the paper - the optimal choice of the Bureaucrat and the Populist.

Define the Bureaucrat's incremental budget between period $t$ and $t-1$ as 


$$
\mathrm{IB} \equiv \mathrm{SB}(\mathrm{t})-\mathrm{SB}(\mathrm{t}-1)=\sum_{\mathrm{j}=\mathrm{k}+1}^{\mathrm{N}} \tau_{\mathrm{j}}\left(\pi_{\mathrm{j}}^{\mathrm{t}}-\tau_{\mathrm{j}}^{\mathrm{t}-1}\right)+\left[-\mathrm{B}_{\mathrm{k}}+\mathrm{S}_{\mathrm{k}}+\tau_{\mathrm{k}} \pi_{\mathrm{k}}^{\mathrm{t}}\right]-\mathrm{I} \cdot \mathrm{T}_{\min } .
$$

Therefore, he will privatize another sector $\mathrm{k}$ if and only if there exists a sector such that $\mathrm{IB} \geq 0$.

When IB $\geq 0$ is satisfied, the Bureaucrat will choose the public sector that gives him the highest surplus budget. Define the maximal budget at time $t$ as

$$
\mathrm{SB}^{*}=\sum_{\mathrm{j}=1}^{\mathrm{k}} \mathrm{B}_{\mathrm{j}}+\sum_{\mathrm{j}=\mathrm{k}+1}^{\mathrm{N}} \tau_{\mathrm{j}} \pi_{\mathrm{j}}^{\mathrm{t}}+\left[-\mathrm{B}_{\mathrm{k}}+\mathrm{S}_{\mathrm{k}}+\tau_{\mathrm{j}} \pi_{\mathrm{j}}^{\mathrm{t}}\right]-\mathbf{I} \cdot \mathrm{T}_{\min } .
$$

It is obvious that maximizing $\mathrm{SB}^{*}$ is equivalent to maximizing IB. We would like to know the characteristics of sector $\mathrm{k}$ that give the Bureaucrat his maximal surplus budget. That is, what kind of sector would he like to choose?

Proposition 3 (The Bureaucrat). For a Bureaucrat, in a large population, his maximal budget increases with a decrease in the market power of sector $\mathrm{k}$; the incremental budget increases with an increase in the amount of subsidy sector $\mathrm{k}$ receives from the government, i.e.,

$$
\frac{\partial \mathrm{SB}^{*}}{\partial \alpha_{\mathrm{k}}}=\frac{\partial \mathrm{IB}}{\partial \alpha_{\mathrm{k}}} \leq 0 \text {, if } \operatorname{Prob}\left\{\theta_{\mathrm{k}} \leq \underline{\mathrm{A}}\right\}=1 ; \text { and } \frac{\partial \mathrm{IB}}{\partial \mathrm{B}_{\mathrm{k}}}=-1 \text {. }
$$

This proposition tells us that in a large population, the Bureaucrat will gain most by privatizing the public sector with the least market power and the largest subsidy first, if all other characteristics of the public sectors are the same. By privatizing the more competitive sector, the price increase as a result of the privatization will be relatively lower. Therefore, the Bureaucrat does not need to compensate the consumers as much, so he can skim off the cream via minimizing the transfers he pays to maintain a certain percentage, $d$, of consumers not worse off by his policy.

As a comparison to the Bureaucrat, we study the optimal policy of the Populist. His constrained maximization problem, (P1) and (P2), can be converted into one of unconstrained maximization by noting that

$$
\begin{aligned}
\mathrm{W}^{\mathrm{t}}= & \sum_{i} \mathrm{v}_{\mathrm{i}}\left(\overrightarrow{\mathrm{P}}^{\mathrm{t}}, \mathrm{y}_{\mathrm{i}}^{\mathrm{t}}\right) \\
= & \sum_{\mathrm{i}} \mu_{\mathrm{i}}\left(\overline{\mathrm{q}}_{1}, \ldots \overline{\mathrm{q}}_{\mathrm{k}-1}, \mathrm{q}_{\mathrm{ik}}^{\mathrm{t}}\left(\overrightarrow{\mathrm{P}}^{\mathrm{t}}\right), \ldots, \mathrm{q}_{\mathrm{iN}}^{\mathrm{t}}\left(\overrightarrow{\mathrm{P}}^{\mathrm{t}}\right)\right)-\sum_{\mathrm{j}=\mathrm{k}}^{\mathrm{N}} \mathrm{P}_{\mathrm{j}}^{\mathrm{t}} \mathrm{Q}_{\mathrm{ij}}^{\mathrm{t}}\left(\overrightarrow{\mathrm{P}}^{\mathrm{t}}\right)+ \\
& \sum_{\mathrm{i}} \mathrm{y}_{\mathrm{i}}+\sum_{\mathrm{j}=\mathrm{k}}^{\mathrm{N}}\left(1-\tau_{\mathrm{j}}\right) \pi_{\mathrm{j}}^{\mathrm{t}}-\mathrm{S}_{\mathrm{k}}-\mathrm{I} \cdot \sum_{\mathrm{j}=1}^{\mathrm{k}-1} \overline{\mathrm{p}}_{\mathrm{j}} \overline{\mathrm{q}}_{\mathrm{j}}+\mathrm{I} \cdot \mathrm{T}
\end{aligned}
$$




$$
=\sum_{i} \mu_{i}\left(\bar{q}_{1}, \ldots, \bar{q}_{k-1}, q_{i k}^{t}\left(\vec{P}^{t}\right), \ldots, q_{i N}^{t}\left(\vec{P}^{\mathfrak{t}}\right)\right)-\sum_{j=k}^{N} C_{j}\left(Q_{j}\right)+\bar{Z}
$$

where $\bar{Z}=\Sigma_{i} y_{i}+\Sigma_{j=1}^{k-1} B_{j}-\Sigma_{j=1}^{k-1} \bar{p}_{j} \bar{Q}_{j}$ is a constant. Therefore, his unconstrained maximization problem is

$$
\max \sum_{\mathrm{i}} \mu_{\mathrm{i}}\left(\overline{\mathrm{q}}_{1}, \ldots, \overline{\mathrm{q}}_{\mathrm{k}-1}, \mathrm{q}_{\mathrm{ik}}^{\mathrm{t}}\left(\overrightarrow{\mathrm{P}}^{\mathrm{t}}\right), \ldots, \mathrm{q}_{\mathrm{iN}}^{\mathrm{t}}\left(\overrightarrow{\mathrm{P}}^{\mathrm{t}}\right)\right)-\sum_{\mathrm{j}=\mathrm{k}}^{\mathrm{N}} \mathrm{C}_{\mathrm{j}}\left(\mathrm{Q}_{\mathrm{j}}\right)
$$

Define the incremental welfare between period $t$ and $t-1$ as

$$
I W=\sum_{i}\left[v_{i}\left(\overrightarrow{\mathrm{P}}^{t}, y_{\mathrm{i}}^{\mathrm{t}}\right)-\mathrm{v}_{\mathrm{i}}\left(\overrightarrow{\mathrm{P}}^{\mathrm{t}-1}, \mathrm{y}_{\mathrm{i}}^{\mathrm{t}-1}\right)\right]
$$

Therefore, he will privatize another sector $\mathrm{k}$ if and only if there exists a sector such that IW $\geq 0$.

Proposition 4 (The Populist). For a Populist, the maximal social welfare increases with a decrease in the market power of sector $\mathrm{k}$, if the sum of weighted marginal utilities for products in the private sectors is greater than or equal to their marginal costs, and vice versa; while the incremental social welfare increases with an increase in subsidy sector $k$ receives when it belongs to the public sector.

$$
\begin{array}{cc}
\partial W^{t} / \partial \alpha_{k} \leq 0, & \text { if } \Sigma_{i} \Sigma_{j=k}^{N}\left(-\frac{\partial q_{i j}}{\partial P_{k}^{t}}\right)\left(\mu_{i j}-M C_{j}\right) \geq 0 \\
\partial W^{t} / \partial \alpha_{k}>0, & \text { otherwise; } \\
\frac{\partial I W}{\partial B_{k}}=-1, &
\end{array}
$$

where $\mu_{\mathrm{ij}}$ is consumer i's marginal utility with respect to product $\mathrm{j}$.

The above proposition shows that holding the other characteristics of the firms in the public sector the same, if the marginal costs of products in the private sectors are not too high relative to marginal utilities, a Populist will privatize the public sector with the least market power and the largest subsidy first. Intuitively, when the marginal costs of products in the private sector are not too high, the dominating effect in the social welfare function is the sum of individuals' indirect utility functions (see (P3)), whose magnitude increases with a decrease of the market power of the newly privatized sector due to the price effect. In this case, privatizing the more competitive sector is the socially most efficient way of privatization. When the marginal costs of products in the 
private sectors are too high with respect to marginal utilities, the dominating effect in the social welfare function is the sum of costs in the private sectors. In this case the Populist will privatize the most monopolistic sector first, since the increase in its prices causes a decrease in the demand of other products, ${ }^{8}$ which causes a decrease in the total cost of production, and hence an increase in the total social welfare. This seemingly perverse result makes sense because the cost of production affects the profit of private firms, all of which goes to the consumers either as profit shares or as compensations from the profit tax to the state, therefore affect the total social welfare.

From the above two propositions, the optimal privatization policy is quite robust to the specification of the politician's objectives. Under ordinary situations, exploiting the more nearly competitive pricing is a faster route to efficiency gain for either type: the one who wants to give adequate capture of efficiency gains to enough citizens at lowest possible rent transfer, and the one who wants to maximize the social welfare when the marginal costs in the existing private sectors are not too high. An interesting but probably unusual case arises when the marginal costs in the private sectors are too high relative to the marginal utilities, when the Populist gains more by privatizing the monopolistic sectors first.

\subsection{Political institutions and the optimal policy}

The above analysis on the Bureaucrat holds the political institution, the percentage of support needed to retain power, constant. It is interesting to know how the privatization processes differ under different political institutions. The following proposition will help us understand how the characteristics of political institutions might affect the Bureaucrat's behavior.

Proposition 5. The maximal surplus budget increases with a decrease in the threshold of the satisfaction level, $d$, i.e., $\frac{\partial \mathrm{SB}^{*}}{\partial \mathrm{d}}<0$.

This proposition shows that in an economy with a smaller $d$, i.e., a less democratic society, the Bureaucrat actually benefits more from the privatization process. If the surplus budget becomes his personal property, he becomes richer consequently. If it is used to ease the operation of the Bureaucracy or privatization process, it could be relatively easier and faster to privatize in a less democratic society. 


\section{Summary and extensions}

From the analysis of the strategies of Public Servants with different objective functions, we can see that the comparative statics results are very similar under ordinary situations. Among the public sectors with all other characteristics the same, each will choose to privatize the sector with the least market power and the largest subsidy from the state. Intuitively speaking, this is the "cheapest" way to privatize from either Public Servant's point of view.

This is a two-period static model. We assumed that the number of firms remained the same. Our results suggest that from the Public Servant's point of view he should encourage measures that can drive down the market power of a sector. An important issue about transition is whether or not large enterprises should be broken up before privatization. Since demonopolization will drive down the market power of that sector, the answer is positive. Another important issue is entry. If we allow entry into the model, it also drives down the market power of any sector, $\alpha_{j}=\frac{1}{L_{j}} \Sigma_{h} \frac{1}{\varepsilon_{j h}}$.

Going back to the sequencing policy discussed in the introduction, we can see that the size of a sector is not the only factor that should be taken into consideration in the Public Servant's optimal policy. Other important factors, such as the subsidy a sector gets, the elasticity of demand of the product, and the competitiveness of a sector (the latter two are included in the concept of the market power index) should all be taken into consideration.

Another assumption is that all goods are non-substitutes to each other. Substitutes are grouped in the same sector. A more realistic approach would do away with this assumption. Such a model would be more complicated, and we are not sure how the result would change. In our model, the wage income of the consumers and the cost functions of firms are taken as exogenously given. Future work should be done to make these factors endogenous within the economy. Some preliminary thinking suggests that the privatization of a sector in the economy would lead to a total change in the supply and demand of labor, and hence the change in wage income. Therefore, for the consumers in a transition economy, both the compensation from the government and the change in their wage income will be the decisive factor in coping with price increases.

Though not exactly a model of the Chinese reform, it sheds some lights on the sequence of reform policies in price liberalization and partial privatization in China over the past decade (Wang and Chern, 1992). Though the political and economic situations in Eastern Europe and ex-Soviet republics are different from China ${ }^{9}$, some of the schemes and sequencing considerations from the Chinese experience can still provide some practical lessons on the likely success and failure of transition toward a market economy.

Although we have focused on the question of the order in which sectors 
would be privatized, a number of normative analyses of privatization risk limited relevance if they do not take account of the political economic factors introduced in this paper.

\section{Notes}

1. This concept is introduced later. It basically captures the competitiveness of the sector and the elasticity of the product. The higher the market power of a sector, the more it can raise the price above marginal cost.

2. There are cases when there is no demand for the output of certain goods at the state-set prices, mostly in the production sector. In these cases, privatization may actually decrease the prices or change the products to something demanded by the market. Since there is little ambiguity in the privatization of these sectors and consumers do not need to be compensated for their privatization, we assume that they are privatized already and hence do not focus our attention on these cases.

3. Here we do not want to make ad hoc assumptions about the effects of privatization on cost, efficiency, or quality.

4. But he does not know the exact utility function of each consumer.

5. Note that the use of the surplus budget does not affect the quantities of public sector goods provided, or the price paid.

6. This is a feasible and practical compensation scheme. It is used in China after each successive "price liberalization"' reform.

7. Proofs of all Propositions are in the Appendix.

8. They are not substitues, by Assumption 4.

9. Most notably, the democratization process that accompanied economic reforms in Eastern Europe and ex-Soviet Union did not occur in China, where strong government control have been maintained in enforcing reform policies.

\section{References}

Bolton, P. and Roland, R. (1992). The Economics of Mass Privatization: Czechslovakia, Germany, Hungary, Poland. Mimeo, Universite Libre de Bruxelles.

Bos, D. (1987). Privatization of public enterprises. European Economic Review 31: 352-360.

Blommestein, H. and Marrese, M. (Ed.). (1991) Transformation of planned economies: Property rights reform and macroeconomic stability. Paris: OECD.

Branco, F. and Mello, A.S. (1991). A theory of partial sales and underpricing in privatization. Mimeo. MIT.

Fiorina, M.P. (1981). Retrospective voting in American national elections. New Haven: Yale University Press.

Grout, P.A. (1988). Employee share ownership and privatization: Some theoretical issues. The Economic Journal 98 (Conference 1988): 97-104.

Li, Y. (1989). Where is Chinese economy going? Hong Kong: Commercial Press.

Lipton, D. and Sachs, J. (1990). Creating a market economy in Eastern Europe: The case of Poland. Brookings Papers on Economic Activity 1:1990.

McMillan, J. and Naughton, B. (1992). How to reform a planned economy: Lessons from China. Oxford Review of Economic Policy 8 (Spring). 
Murphy, K.M., Shleifer, A. and Vishny, R.W. (1991). The transition to a market economy: Pitfalls of partial planning reform. Mimeo. University of Chicago and Harvard University.

Niskanen, W.A. (1971). Bureaucracy and representative government. Chicago and New York: Aldine, Atherton.

Novshek, W. (1985). On the existence of Cournot equilibrium. Review of Economic Studies 52: 89-98.

Tirole, J. (1988). The theory of industrial organization. Cambridge: MIT Press.

Tirole, J. (1991). Ownership and incentives in a transition economy. Mimeo. MIT.

Wang, Z. and Chern, W.S. (1992). Effects of rationing on the consumption behavior of Chinese households during 1981-1987. Journal of Comparative Economics 16: 1-26.

\section{Appendix}

\section{Proof of Proposition 1}

Substituting $S_{k}=\left(1+\varepsilon_{k}\right)\left(1-\tau_{k}\right) \pi_{k}$ into $T_{i}^{*}$, we get

$$
\mathrm{T}_{\mathrm{i}}^{*}=\varphi_{\mathrm{i}}\left(\overrightarrow{\mathrm{P}}^{\mathrm{t}-1}\right)-\varphi_{\mathrm{i}}\left(\overrightarrow{\mathrm{P}}^{\mathrm{t}}\right)+\sum_{\mathrm{j}=\mathrm{k}+1}^{\mathrm{N}} \theta_{\mathrm{ij}}\left(1-\tau_{\mathrm{j}}\right)\left(\pi_{\mathrm{j}}^{\mathrm{t}-1}-\pi_{\mathrm{j}}^{\mathrm{t}}\right)+\theta_{\mathrm{ik}} \varepsilon_{\mathrm{k}}\left(1-\tau_{\mathrm{k}}\right) \pi_{\mathrm{k}}^{\mathrm{k}}-\overline{\mathrm{P}}_{\mathrm{k}} \overline{\mathrm{q}}_{\mathrm{k}} .
$$

Differentiate $T_{i}^{*}$ with respect to $P_{k}^{t}$,

$$
\frac{\partial T_{i}^{*}}{\partial \mathbf{P}_{k}^{t}}=-\frac{\partial \varphi_{i}\left(\vec{P}^{t}\right)}{\partial \mathbf{P}_{k}^{t}}-\sum_{j=k+1}^{N} \theta_{i j}\left(1-\tau_{j}\right) \frac{\partial \pi_{j}^{t}}{\partial P_{k}^{t}}+\theta_{i k} \varepsilon_{k}\left(1-\tau_{k}\right) \frac{\partial \pi_{k}^{t}}{\partial \mathbf{P}_{k}^{t}}
$$

Since $\frac{\partial \theta_{i}\left(\vec{P}^{t}\right)}{\partial \mathbf{P}_{k}^{t}} \leq 0$, the first term is positive.

Differentiating $\pi_{\mathrm{lj}}=\mathrm{P}_{\mathrm{j}} \mathrm{Q}_{\mathrm{lj}}(\overrightarrow{\mathrm{P}})-\mathrm{C}_{\mathrm{j}}\left(\mathrm{Q}_{\mathrm{lj}}(\overrightarrow{\mathrm{P}})\right)$ with respect to $\mathrm{P}_{\mathrm{k}}$, we have

$$
\frac{\partial \pi_{\mathrm{lj}}}{\partial \mathrm{P}_{\mathrm{k}}}=\frac{\partial \mathrm{Q}_{\mathrm{j}}\left(\overrightarrow{\mathrm{P}}^{\mathrm{t}}\right)}{\partial \mathrm{P}_{\mathrm{k}}^{t}}\left[\mathbf{P}_{\mathrm{j}}-\mathrm{MC}_{\mathrm{j}}\left(\mathrm{Q}_{\mathrm{j}}\right)\right] \leq 0
$$

by Assumption (4), so the second term is also positive.

Since the profit in sector $\mathbf{k}$ can increase or decrease with an increase in the price of product $k$, the sign of $\frac{\partial \pi_{\mathrm{k}}^{\mathrm{t}}}{\partial \mathrm{P}_{\mathrm{k}}^{\mathrm{t}}}$ is ambiguous.

(1) If $\varepsilon_{\mathrm{k}} \frac{\partial \pi_{\mathrm{k}}^{\mathrm{t}}}{\partial \mathrm{P}_{\mathrm{k}}^{\mathrm{t}}} \geq 0$, then we have $\frac{\partial \mathrm{T}_{\mathrm{i}}^{*}}{\partial \mathrm{P}_{\mathrm{k}}^{\mathrm{t}}} \geq 0$.

(2) If $\varepsilon_{\mathrm{k}} \frac{\partial \pi_{\mathrm{k}}^{\mathrm{t}}}{\partial \mathrm{P}_{\mathrm{k}}^{\mathrm{t}}}<0$, however, the exact change in the amount of compensation caused by the change in the price of product $\mathrm{k}$ depends on the proportion of shares he holds in sector $\mathrm{k}$.

When $0 \leq \theta_{i k} \leq A_{i}$, we have $\frac{\partial T_{i}^{*}}{\partial \mathrm{P}_{k}^{t}} \geq 0$. On the other hand, if $\theta_{i k}>A_{i}$, we have $\frac{\partial T_{i}^{*}}{\partial P_{k}^{t}}<0$.

Since $P_{j}=\frac{M C_{j}}{1-\alpha_{j}}$, it follows that $\frac{\partial \rho_{k}^{t}}{\partial \alpha_{k}^{t}}>0$. We know that $\frac{\partial T_{i}^{*}}{\partial \alpha_{k}}=\frac{\partial T_{i}^{*}}{\partial P_{k}^{t}} \frac{\partial P_{k}^{t}}{\partial \alpha_{k}}$. Therefore, the sign of $\frac{\partial \mathrm{T}_{\mathrm{i}}^{*}}{\partial \alpha_{\mathrm{k}}}$ is the same as the sign of $\frac{\partial \mathrm{T}_{\mathrm{i}}^{*}}{\partial \mathrm{P}_{\mathrm{k}}^{t}}$. 


\section{Proof of Proposition 2}

Since d,

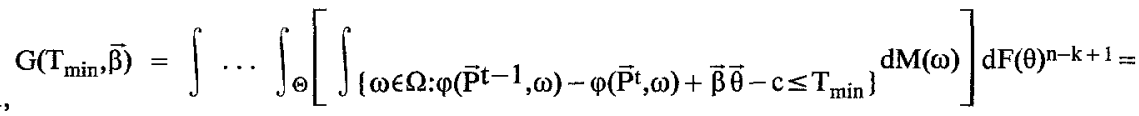

Let $\mathbf{T} \equiv \phi\left(\overrightarrow{\mathrm{P}}^{t-1}, \omega\right)-\phi\left(\overrightarrow{\mathbf{P}}^{t}, \omega\right)+\vec{\beta} \vec{\theta}-c$. First, we want to show that $\frac{\partial \mathrm{T}}{\partial \mathrm{P}_{\mathrm{k}}^{\mathrm{t}}} \geq 0, \forall \omega, \vec{\theta}$, if Prob $\left\{\theta_{\mathrm{k}} \leq \underline{\mathrm{A}}\right\}=1$.

Differentiating $\mathrm{T}$ with respect to $\mathrm{P}_{\mathrm{k}}^{\mathrm{t}}$, we get

$$
\frac{\partial \mathrm{T}}{\partial \mathrm{P}_{\mathrm{k}}^{\mathrm{t}}}=-\frac{\partial \theta\left(\overrightarrow{\mathrm{P}}^{\mathrm{t}}, \omega\right)}{\partial \mathrm{P}_{\mathrm{k}}^{\mathrm{t}}}-\sum_{\mathrm{j}=\mathrm{k}+1}^{\mathrm{N}} \theta_{\mathrm{j}}\left(1-\tau_{\mathrm{j}}\right) \frac{\partial \pi_{\mathrm{j}}^{\mathrm{t}}}{\partial \mathrm{P}_{\mathrm{k}}^{\mathrm{t}}}+\theta_{\mathrm{k}} \varepsilon_{\mathrm{k}}\left(1-\tau_{\mathrm{k}}\right) \frac{\partial \pi_{\mathrm{k}}^{\mathrm{t}}}{\partial \mathrm{P}_{\mathrm{k}}^{\mathrm{t}}} .
$$

From the proof of Proposition 1, we know that the first two terms are both positive, while the sign of the third term is ambiguous.

(1) If $\varepsilon_{\mathrm{k}} \frac{\partial \pi_{\mathrm{k}}^{\mathrm{t}}}{\partial \mathrm{P}_{\mathrm{k}}^{\mathrm{t}}} \geq 0$, then we have $\frac{\partial \mathrm{T}}{\partial \mathrm{P}_{\mathrm{k}}^{\mathrm{t}}} \geq 0$.

(2) If $\varepsilon_{\mathrm{k}} \frac{\partial \pi_{\mathrm{k}}^{\mathrm{t}}}{\partial \mathrm{P}_{\mathrm{k}}^{\mathrm{t}}}<0$, we need more conditions to decide the sign of $\frac{\partial \mathrm{T}}{\partial \mathrm{P}_{\mathrm{k}}^{\mathrm{t}}}$. Let $\mathrm{A}=$

$$
\frac{\frac{\partial \phi\left(\vec{P}^{t}, \omega\right)}{\partial \mathrm{P}_{k}^{t}}+\Sigma_{j=k+1}^{N} \theta_{j}\left(1-\tau_{j}\right) \frac{\partial \pi_{j}^{t}}{\partial \mathrm{P}_{k}^{t}}}{\varepsilon_{k}\left(1-\tau_{k}\right) \frac{\partial \pi_{k}^{t}}{\partial P_{k}^{t}}} \text {. Note that there are two kinds of distributions in A: the index }
$$

of utility functions, $\omega$, and the proportion of shares in the existing private sectors, $\theta_{\mathrm{j}}, \mathrm{j}=\mathrm{k}+$ $1, \ldots, N$. Since $\phi\left(\overrightarrow{\mathrm{P}}^{t}, \omega\right)$ is decreasing in $\mathrm{P}$, and strictly increasing in $\omega$, we use $\underline{\omega}$ to denote the highest absolute value of $\frac{\partial \theta\left(\overrightarrow{\mathbf{P}}^{\mathrm{t}}, \omega\right)}{\partial \mathbf{P}_{\mathrm{k}}^{\mathrm{t}}}$, and $\bar{\omega}$ to denote its lowest absolute value. Then it follows that the lower bound of $\mathrm{A}$ is

$$
\underline{\mathrm{A}}=\frac{\frac{\partial \varphi\left(\overrightarrow{\mathrm{P}}^{\mathrm{t}}, \bar{\omega}\right)}{\partial \mathrm{P}_{\mathrm{k}}^{\mathrm{t}}}}{\varepsilon_{\mathrm{k}}\left(1-\tau_{\mathrm{k}}\right) \frac{\partial \pi_{\mathrm{k}}^{\mathrm{t}}}{\partial \mathrm{P}_{\mathrm{k}}^{\mathrm{t}}}} .
$$

Therefore, if $\operatorname{Prob}\left\{\theta_{\mathrm{k}} \leq \underline{\mathbf{A}}\right\}=1$, we have $\frac{\partial \mathrm{T}}{\partial \mathrm{P}_{\mathrm{k}}^{\mathrm{t}}} \geq 0, \forall \omega, \vec{\theta}$.

Next, we want to show that $T_{\min }$ has a similar property. It follows from the first part of the proof that for any $P_{k}^{\prime t} \geq P_{k}$, if $\operatorname{Prob}\left\{\theta_{k} \leq \underline{A}\right\}=1$, we have $T^{\prime} \geq T, \forall \omega, \vec{\theta}$. We want to show that $T_{\min }^{\prime} \geq T_{\min }$, where $T_{\min }^{\prime}$ satisfies

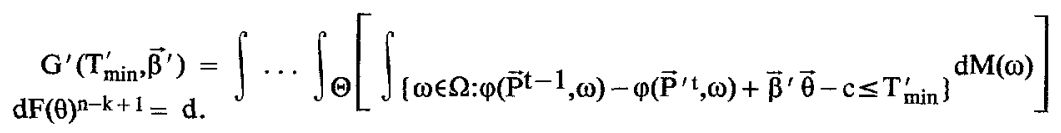


Suppose not, then $T_{\min }^{\prime}<T_{\min }$. Let $A=\left\{\omega \in \Omega: T^{\prime} \leq T_{\min }\right\}$, and $B=\left\{\omega \in \Omega: T \leq T_{\min }\right\}$. Since $T^{\prime} \geq T$, it follows that $A \subseteq B$. We know that

$$
\int \cdots \int_{\Theta}\left[\int_{B} \mathrm{dM}(\omega)\right] \mathrm{dF}(\theta)^{\mathrm{n}-\mathrm{k}+1}=\mathrm{d} .
$$

It follows that

$$
\int \cdots \int_{\Theta}\left[\int_{A} \mathrm{dM}(\omega)\right] d F(\theta)^{n-k+1} \leq d .
$$

Let $C=\left\{\omega \in \Omega: T^{\prime} \leq T_{\min }^{\prime}\right\}$. Since $T_{\min }>T_{\min }^{\prime}$, we have $C \subset A$. Therefore,

$$
\int \cdots \int_{\Theta}\left[\int_{C} d M(\omega)\right] d F(\theta)^{n-k+1}<d,
$$

but this contradicts the definition of $T_{\min }^{\prime}$. So $T_{\min }^{\prime} \geq T_{\min }$. Then we have $\frac{\partial T_{\min }}{\partial \mathrm{P}_{k}^{t}} \geq 0$, and equivalently, $\frac{\partial \mathrm{T}_{\min }}{\partial \alpha_{\mathrm{k}}} \geq 0$.

Finally, we want to show that $\operatorname{Prob}\left\{\theta_{\mathrm{k}} \leq \underline{\mathbf{A}}\right\}=1$ holds in a large population.

$$
\operatorname{Prob}\left\{\theta_{\mathrm{k}} \leq \underline{\mathbf{A}}\right\}=1-\operatorname{Prob}\left\{\theta_{\mathrm{k}} \leq \underline{\mathbf{A}}\right\}=1-\frac{\left|\mathrm{i}: \theta_{\mathrm{ik}}>\underline{\mathbf{A}}\right|}{\mathrm{I}},
$$

Since $\Sigma_{\mathrm{i}=1}^{\mathrm{I}} \theta_{\mathrm{ik}}=1,\left|\mathrm{i}: \theta_{\mathrm{ik}}>\underline{\mathbf{A}}\right|<\min \operatorname{int}\left[\frac{1}{\underline{\mathrm{A}}}\right]$, which is bounded and independent of $\mathrm{I}$. Therefore, as $I \rightarrow+\infty, \frac{\left|\mathrm{i}: \theta_{\mathrm{ik}}>\underline{\mathrm{A}}\right|}{\mathrm{I}} \rightarrow 0$, we have

$$
\operatorname{Prob}\left\{\theta_{\mathrm{k}} \leq \underline{\mathbf{A}}\right\}=1-\frac{\left|\mathrm{i}: \theta_{\mathrm{ik}}>\underline{\mathrm{A}}\right|}{\mathrm{I}}=1 \text {. }
$$

\section{Proof of Proposition 3}

Differentiating $\mathrm{SB}^{*}$ and $\mathrm{IB}$ with respect to $\mathrm{P}_{\mathrm{k}}^{\mathrm{t}}$, we get

$$
\begin{aligned}
\frac{\partial \mathrm{SB}^{*}}{\partial \mathrm{P}_{\mathrm{k}}^{\mathrm{t}}}=\frac{\partial \mathrm{IB}}{\partial \mathrm{P}_{\mathrm{k}}^{\mathrm{t}}} & =\sum_{\mathrm{j}=\mathrm{k}+1}^{\mathrm{N}} \tau_{\mathrm{j}} \frac{\partial \pi_{\mathrm{j}}^{\mathrm{t}}}{\partial \mathrm{P}_{\mathrm{k}}^{\mathrm{t}}}+\tau_{\mathrm{k}} \frac{\partial \pi_{\mathrm{k}}^{\mathrm{t}}}{\partial \mathrm{P}_{\mathrm{k}}^{\mathrm{t}}}-\mathrm{I} \frac{\partial \mathrm{T}_{\min }}{\partial \mathrm{P}_{\mathrm{k}}^{\mathrm{t}}} \\
& =\mathrm{I}\left[\frac{1}{\mathrm{I}}\left(\sum_{\mathrm{j}=\mathrm{k}+1}^{\mathrm{N}} \tau_{\mathrm{j}} \frac{\partial \pi_{\mathrm{j}}^{\mathrm{t}}}{\partial \mathrm{P}_{\mathrm{k}}^{\mathrm{t}}}+\tau_{\mathrm{k}} \frac{\partial \pi_{\mathrm{k}}^{\mathrm{t}}}{\partial \mathrm{P}_{\mathrm{k}}^{\mathrm{t}}}\right)-\frac{\partial \mathrm{T}_{\min }}{\partial \mathrm{P}_{\mathrm{k}}^{\mathrm{t}}}\right] .
\end{aligned}
$$

When I $\rightarrow+\infty$, we have $\frac{1}{\mathrm{I}}\left(\sum_{\mathrm{j}-\mathrm{k}+1} \frac{\partial \pi_{\mathrm{j}}^{\mathrm{t}}}{\partial \mathrm{P}_{\mathrm{k}}^{\mathrm{t}}}+\tau_{\mathrm{k}} \frac{\partial \pi_{\mathrm{k}}^{\mathrm{t}}}{\partial \mathrm{P}_{\mathrm{k}}^{\mathrm{t}}}\right) \rightarrow 0$; also, from Proposition 2, it follows that when $\mathrm{I} \rightarrow+\infty, \operatorname{Prob}\left\{\theta_{\mathrm{k}} \leq \underline{\mathrm{A}}\right\}=1$, and thus $\frac{\partial \mathrm{T}_{\min }}{\partial \mathrm{P}_{\mathrm{k}}^{\mathrm{t}}} \geq 0$. Therefore, $\frac{\partial \mathrm{SB}^{*}}{\partial \mathrm{P}_{\mathrm{k}}^{\mathrm{t}}}=$ $\frac{\partial \mathrm{IB}}{\partial \mathrm{P}_{\mathrm{k}}^{\mathrm{t}}} \leq 0$, and $\frac{\partial \mathrm{SB}^{*}}{\partial \alpha_{\mathrm{k}}}=\frac{\partial \mathrm{IB}}{\partial \alpha_{\mathrm{k}}} \leq 0$.

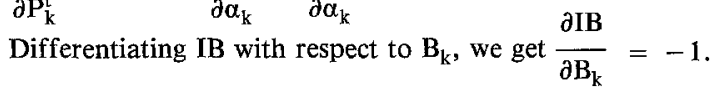




\section{Proof of Proposition 4}

$$
\begin{aligned}
\frac{\partial W^{t}}{\partial P_{k}^{t}} & =\sum_{j=k}^{N} \sum_{i}^{N} \frac{\partial \mu_{i}}{\partial q_{i j}} \frac{\partial q_{i j}}{\partial P_{k}^{t}}-\sum_{j=k}^{N} M C_{j} \frac{\partial Q_{j}}{\partial P_{k}^{t}} \\
& =\sum_{j=k}^{N} \sum_{i}^{N} \frac{\partial q_{i j}}{\partial P_{k}^{t}}\left[\mu_{i j}-M C_{j}\right] .
\end{aligned}
$$

Proof of Proposition 5

Differentiate $\mathrm{SB}^{*}$ with respect to $d$, and apply $\partial \mathrm{T}_{\min } / \partial \mathrm{d} \geq 0$.

QED 